Supporting Information

\title{
Synthesis of a nonavalent mannoside glycodendrimer based on pentaerythritol
}

\author{
Hussein Al-Mughaid and T. Bruce Grindley* \\ Department of Chemistry, Dalhousie University, Halifax, N.S., B3H 4J3 Canada
}

*Corresponding Author: T. Bruce Grindley Email: Bruce.Grindley@Dal.Ca

Telephone: 902-494-2041

Fax: 902-494-1310

\section{Table of Contents for Supporting Information}

First file: Part 1.

General Methods

Materials

S5

$\begin{array}{ll}\text { References for supporting information } & \text { S6 }\end{array}$

$\begin{array}{ll}\text { NMR spectra of compound } 2 \text { in chloroform- } d & \text { S7 }\end{array}$

$250.13 \mathrm{MHz}{ }^{1} \mathrm{H}$ NMR spectrum of compound 3 in chloroform- $d$ S $\quad$ S8

$62.9 \mathrm{MHz}{ }^{13} \mathrm{C}$ NMR spectrum of compound 3 in chloroform- $d$. S9

62.9 $\mathrm{MHz}{ }^{13} \mathrm{C}$ NMR spectrum of compound 4 in chloroform- $d . \quad \mathrm{S} 10$

62.9 $\mathrm{MHz}{ }^{13} \mathrm{C}$ NMR spectrum of compound 5 in chloroform- $d$. S11

62.9 MHz ${ }^{13} \mathrm{C}$ NMR spectrum of compound 6 in chloroform-d. $\quad$ S12

Part of the $500.13 \mathrm{MHz}{ }^{1} \mathrm{H}$ NMR spectrum of compound $\mathbf{1 0}$ in chloroform-d. $\quad$ S13

125.8 MHz ${ }^{13} \mathrm{C}$ NMR spectrum of compound $\mathbf{1 0}$ in chloroform-d. $\quad \mathrm{S} 14$

ESI mass spectrum of compound $\mathbf{1 0}$ on an ion-trap mass spectrometer. $\quad$ S15

Part of the $500.13 \mathrm{MHz}{ }^{1} \mathrm{H}$ NMR spectrum of compound $\mathbf{1 1}$ in chloroform-d. S16

125.8 MHz ${ }^{13} \mathrm{C}$ NMR spectrum of compound $\mathbf{1 1}$ in chloroform-d. S17 
The molecular ion region of the MALDI mass spectrum of compound $\mathbf{1 1}$ recorded on a 9.4 T FT-ICR mass spectrometer.

$250.13 \mathrm{MHz}{ }^{1} \mathrm{H}$ NMR spectrum of compound 13 in dimethyl sulfoxide- $d_{6}$.

250.13 MHz ${ }^{1} \mathrm{H}$ NMR spectrum of compound 15 in chloroform-d.

The molecular ion region of the MALDI mass spectrum of compound 23 recorded on a 9.4 T FT-ICR mass spectrometer. 
125.8 MHz ${ }^{13} \mathrm{C}$ NMR spectrum of compound 25 in methanol- $d_{4}$.

DEPT 135 spectrum of compound 25 in methanol- $d_{4}$. 
General Methods. Melting points are uncorrected. ${ }^{1} \mathrm{H}$ and ${ }^{13} \mathrm{C}$ NMR spectra were recorded at $300 \mathrm{~K}$ in $5 \mathrm{~mm}$ NMR tubes on $250 \mathrm{MHz}$ or $500 \mathrm{NMR}$ spectrometers operating at 250.13 or 500.13 MHz for ${ }^{1} \mathrm{H}$ NMR spectra and 62.9 or $125.77 \mathrm{MHz}$ for ${ }^{13} \mathrm{C}$ NMR spectra, respectively, on solutions in chloroform-d, unless otherwise indicated. Chemical shifts are given in parts per million $(\mathrm{ppm})(+/-0.01 \mathrm{ppm})$ relative to that of tetramethylsilane $(\mathrm{TMS})(0.00 \mathrm{ppm})$ in the case of ${ }^{1} \mathrm{H}$ NMR spectra, and to the central line of chloroform-d (77.16 ppm) for ${ }^{13} \mathrm{C}$ NMR spectra. All assignments were confirmed by COSY, HETCOR, HSQC, DEPT or HMBC experiments. Compounds whose mass spectra were obtained using electron ionization $(70 \mathrm{eV})$ were measured on a double focusing mass spectrometer. Low resolution electron mass spectra (LR ESI MS) were recorded on ion trap mass spectrometers. Mass spectra for compounds 11, 23 and 25 were run on an FT-ICR mass spectrometer equipped with an internal vacuum MALDI source and an actively shielded $9.4 \mathrm{~T}$ magnet. Samples (about $1 \mathrm{pMol}$ ) with an equimolar amount of sodium acetate and a thousand-fold excess of 2,5-dihydroxybenzoic acid were spotted on a stainless steel plate and irradiated with a laser operating at $355 \mathrm{~nm}$ and $15 \mathrm{~mJ}$ per pulse. Ions were generated by $20-50$ pulses at $40-60 \%$ of full laser power and stored in a linear ion trap before being pulsed through a quadrupole ion guide into the ion cyclotron resonance (ICR) cell where they were activated by a waveform of adequate frequency range to cover the desired $\mathrm{m} / \mathrm{z}$ range. Broadband detection was used and typically 4,194,304 data points were collected at an ADC rate of $1 \mathrm{MHz}$ for a transient length of $4.194 \mathrm{~s}$. The data were Fourier transformed using a Blackman window function with one zero fill. Spectra were calibrated using internal PEG standards. Optical rotations were determined with an automatic polarimeter. Benzylidene acetals were visualized on TLC by quenching of fluoresence or by spraying the plate with a solution of $0.2 \% p$ methoxyphenol in ethanol/2 $\mathrm{N} \mathrm{H}_{2} \mathrm{SO}_{4}(1 / 1, \mathrm{v} / \mathrm{v})^{1}$ and heating the TLC plate until color developed. 
Other compounds were visualized by quenching of fluoresence where applicable and/or were located by spraying with a solution of $2 \%$ ceric sulfate in $1 \mathrm{M}$ sulfuric acid followed by heating until color developed. Compounds were purified on silica gel TLC standard grade (230-400 mesh) by flash chromatography using specified eluents.

Materials. Pentaerythritol, trimethylsilyl trifluoromethanesulfonate $(99 \%)$ and $N, N-$ diisopropylamine (redistilled, 99.95\%) were purchased and used as received. Pentaerythritol triO-allyl ether (1, 70\% purity) (now available as pentaerythritol allyl ether) was purified by flash column chromatography on silica gel (pure hexanes to EtOAc:hexanes, 1:7). Tetrahydrofuran (THF) was distilled from sodium benzophenone prior to use. $\mathrm{MeOH}$ was dried by distillation from magnesium turnings. Dichloromethane was first dried with calcium chloride, and then refluxed over calcium hydride for one hour followed by distillation. Dimethylformamide (DMF) was stored over activated $4 \AA$ molecular sieves for $72 \mathrm{~h}$. It was then distilled under reduced pressure over freshly activated $4 \AA$ molecular sieves. 5,5-Bis(hydroxymethyl)-2-phenyl-1,3dioxane was prepared according to the procedure reported by Issidorides et al. $^{2}$ 5,5Bis(hydroxymethyl)-2-(p-methoxyphenyl-1,3-dioxane (13) was prepared according to the procedure reported by Auguilera et al. $^{3}$ 2,3,4,6-Tetra-O-benzoyl- $\alpha$-D-mannopyranosyl trichloroacetimidate (9) was synthesized according to the known protocol. ${ }^{4} 1,2,3,4,6$-penta-Obenzoyl- $\alpha, \beta$-D-mannopyranoside (7) was prepared according to the procedure reported by Ness et al. ${ }^{5}$ 5,5-Bis(acetoxymethyl)-2-(p-methoxyphenyl)-1,3-dioxane (14) was prepared by the method reported by El Ashry et al. ${ }^{6}$ All of these compounds had physical constants that matched literature values. 


\section{References for Supporting Information}

1. Herzner, H.; Eberling, J.; Schultz, M.; Zimmer, J.; Kunz, H. J. Carbohydr. Chem. 1998, 17, 759-776.

2. Issidorides, C. H.; Gulen, R. C. In Organic Syntheses Collected Volume IV; Edited by Rabjohn, N., Ed.; John Wiley and Sons: New York, 1963; pp 679-681.

3. Aguilera, B.; Romero-Ramírez, L.; Abad-Rodríguez, J.; Corrales, G.; Nieto-Sampedro, M.; Fernández-Mayoralas, A. J. Med. Chem. 1998, 41, 4599-4606.

4. Bien, F.; Ziegler, T. Tetrahedron: Asymmetry 1998, 9, 781-790.

5. Ness, R. K.; Fletcher, H. G., Jr.; Hudson, C. S. J. Am. Chem. Soc. 1950, 72, 2200-2205.

6 El Ashry, E. S. H.; El Kilany, Y.; Hamid, H. A.; El-Zemity, S. R.; Boghdady, S. J. Chem. Research (S) 2003, 111-128. 
NMR spectra of compound 2 in chloroform-d: Top, $250.13 \mathrm{MHz}{ }^{1} \mathrm{H}$ NMR spectrum; bottom, 62.9 $\mathrm{MHz}{ }^{13} \mathrm{C}$ NMR spectrum. Note that assignments are provided in the experimental section.

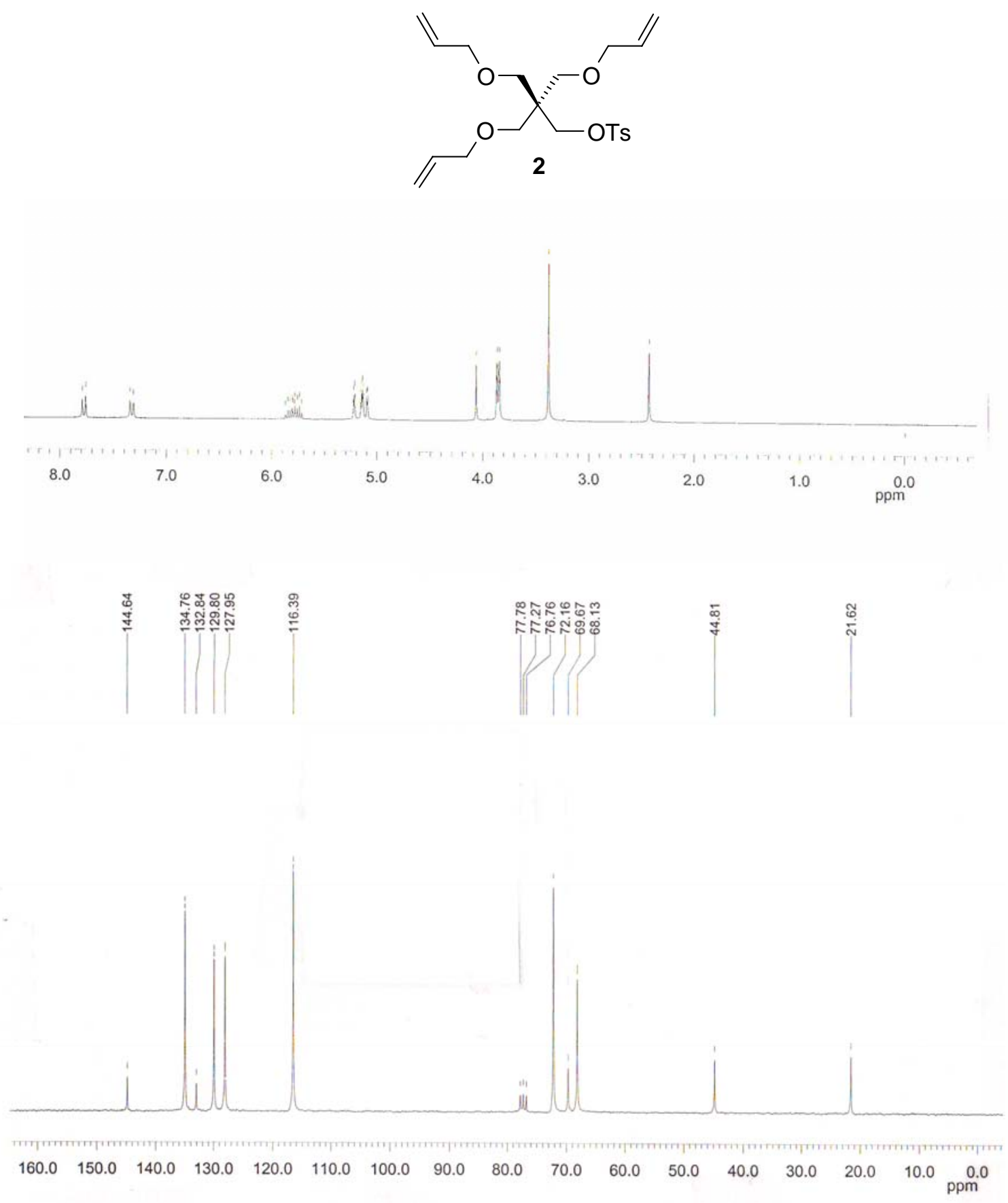


250.13 MHz ${ }^{1} \mathrm{H}$ NMR spectrum of compound 3 in chloroform- $d$.
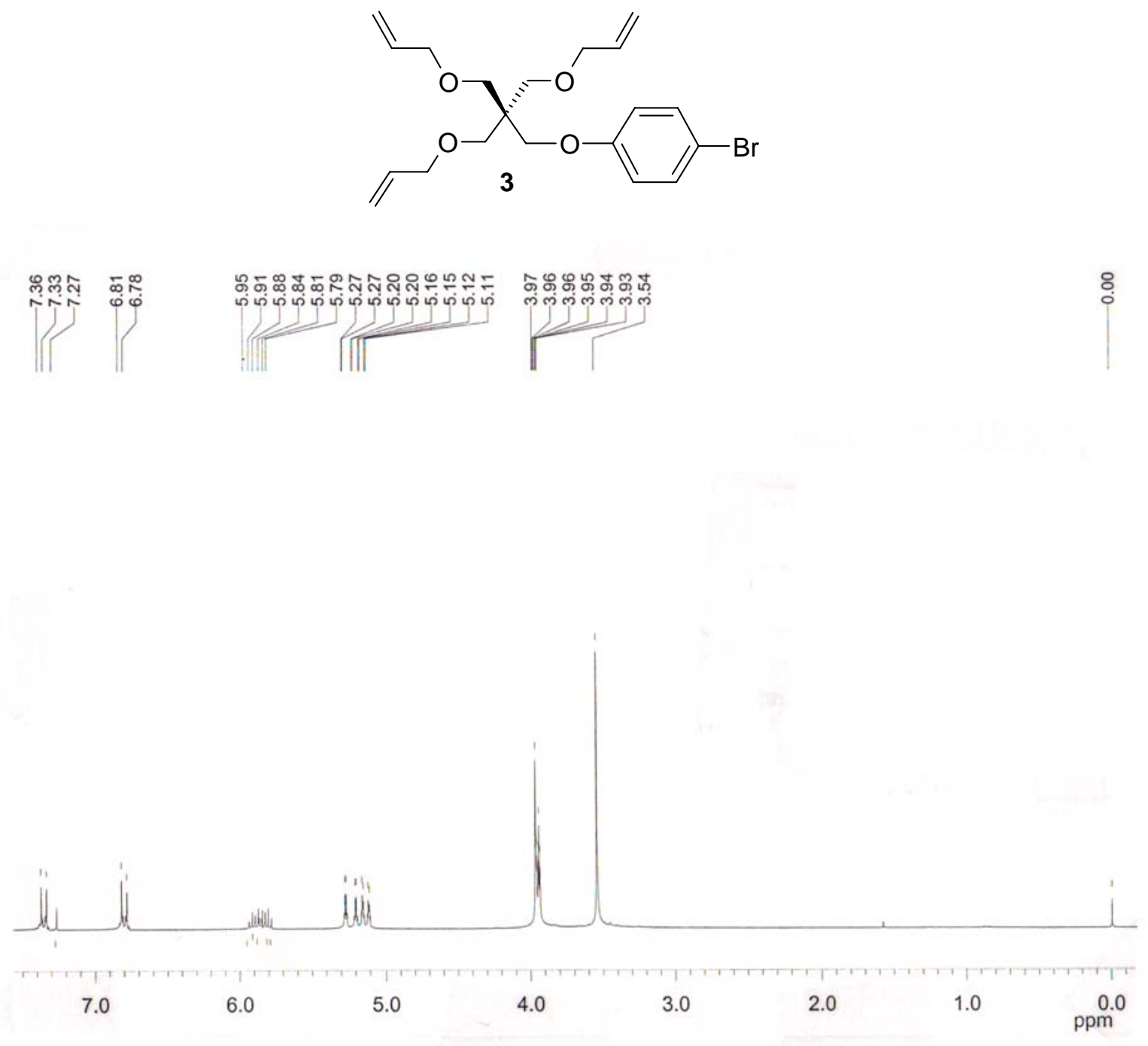
62.9 MHz ${ }^{13} \mathrm{C}$ NMR spectrum of compound 3 in chloroform- $d$.
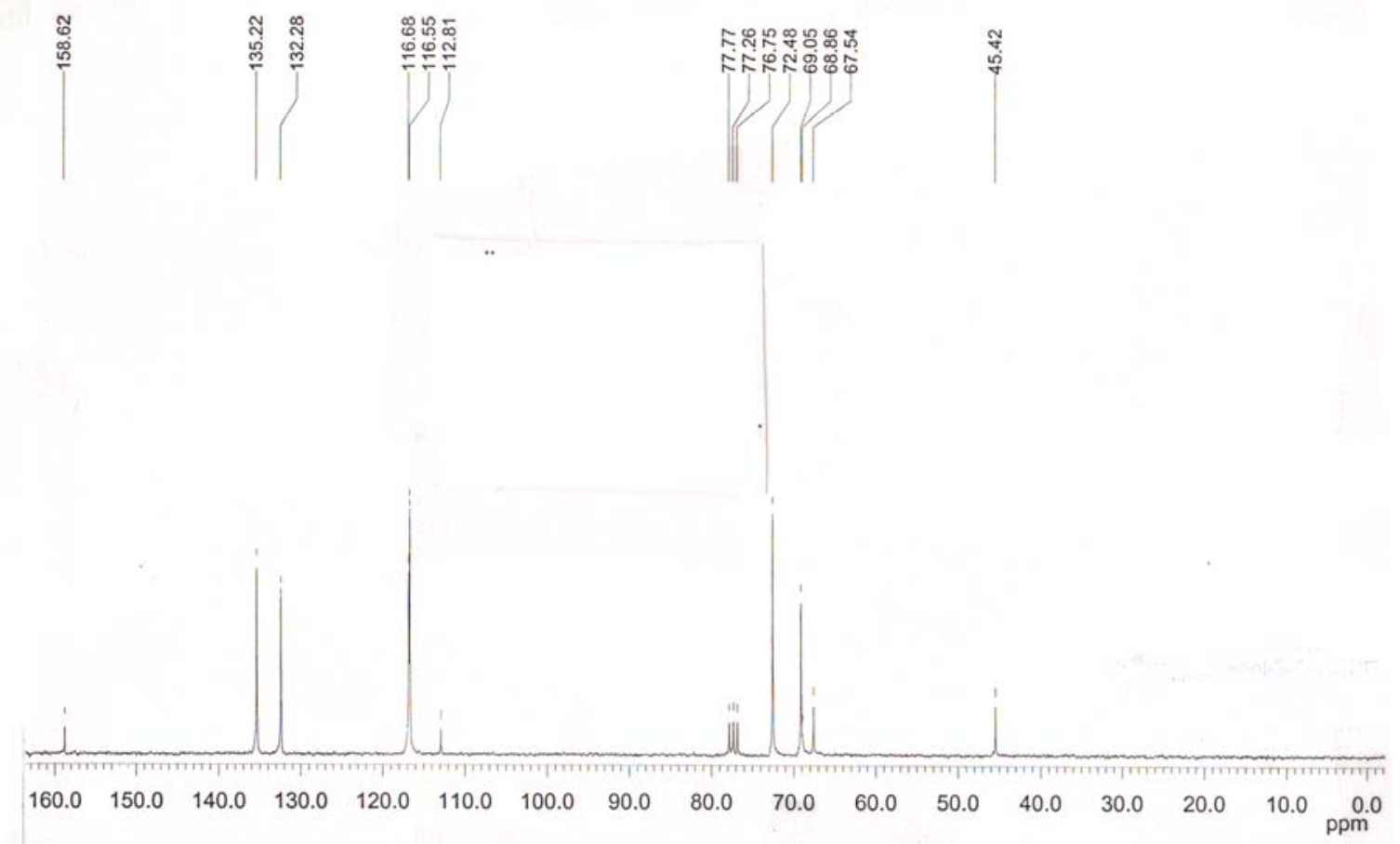
62.9 MHz ${ }^{13} \mathrm{C}$ NMR spectrum of compound 4 in chloroform-d.
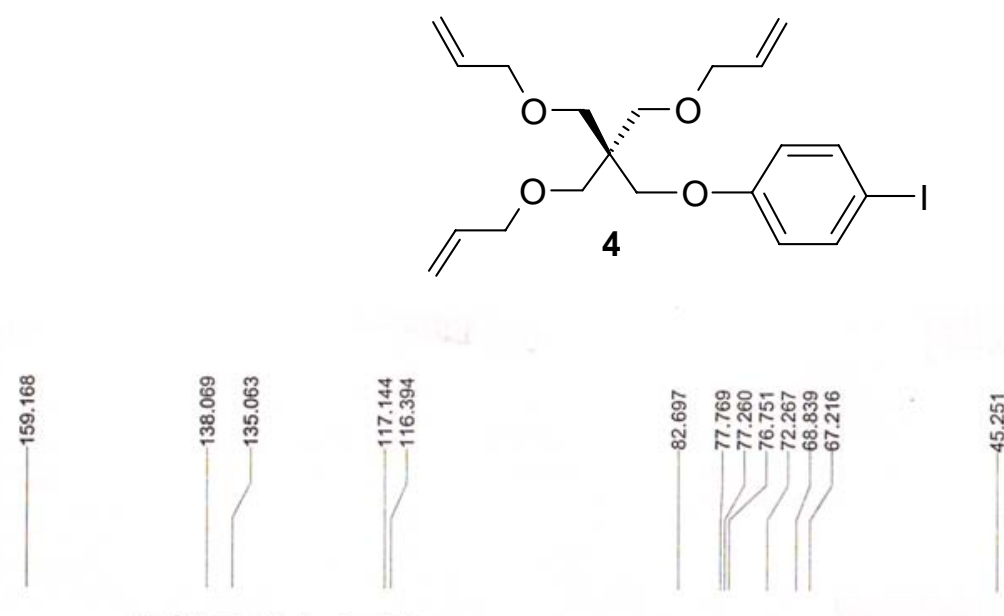

PE(OALL)3-P-iodophenyl\#4
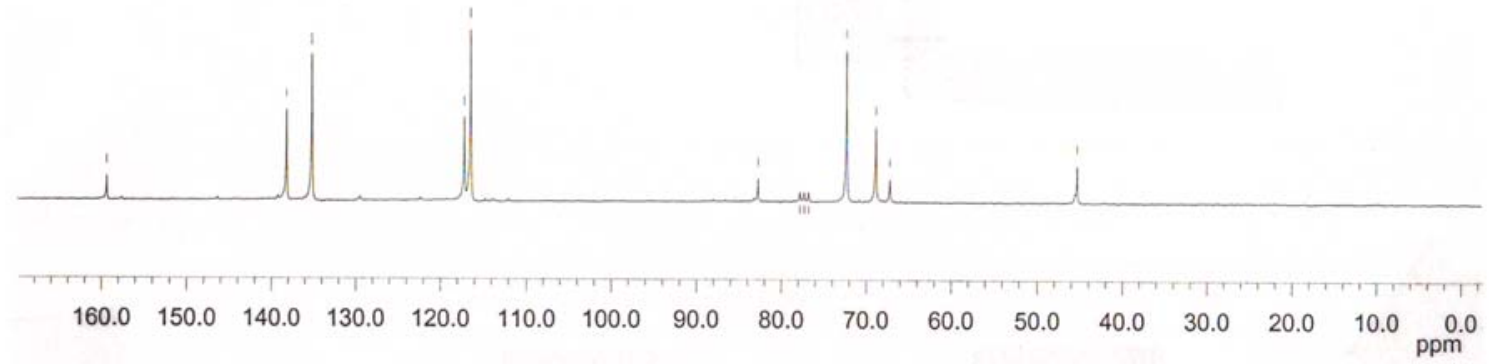
62.9 MHz ${ }^{13} \mathrm{C}$ NMR spectrum of compound 5 in chloroform- $d$.

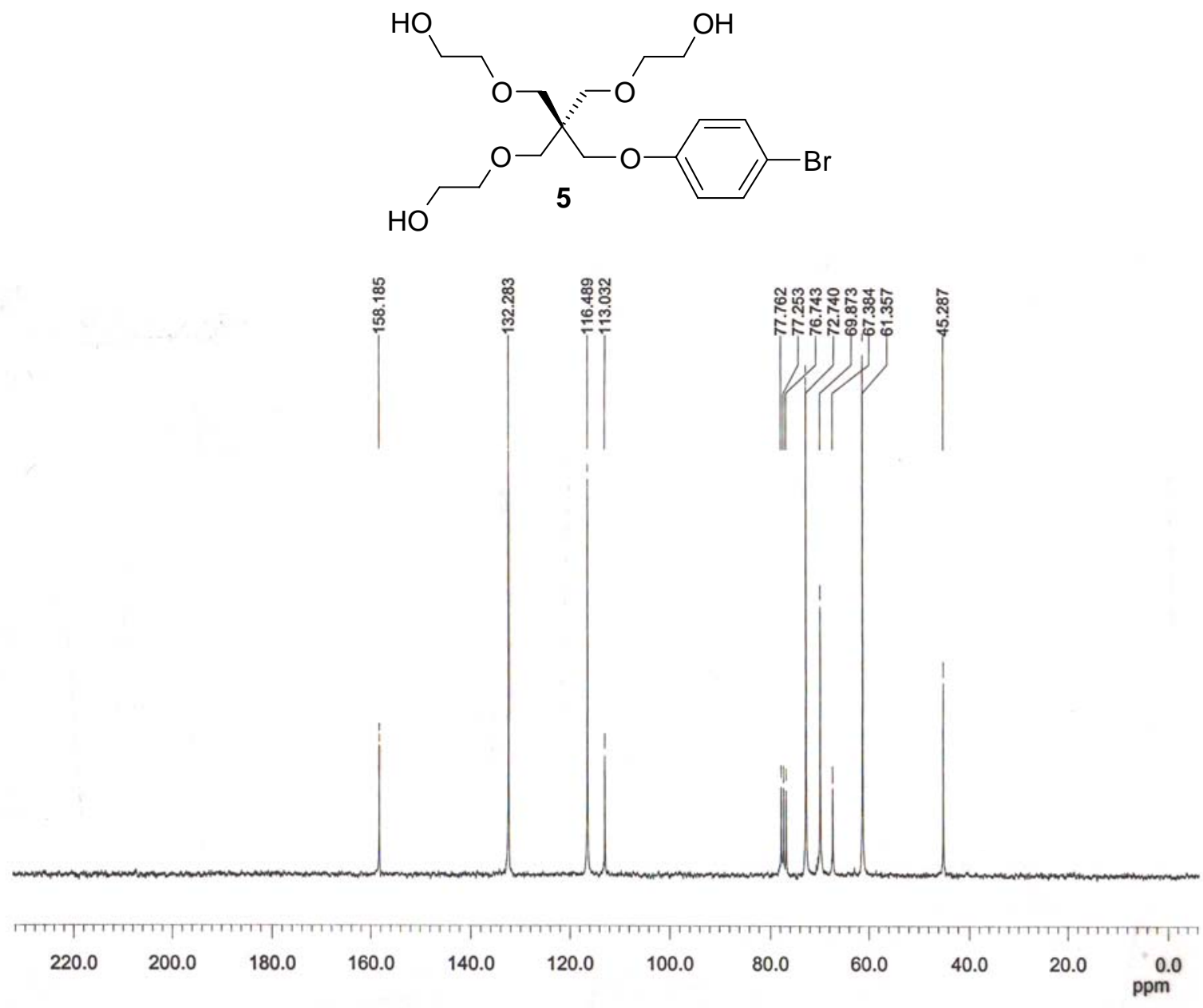


62.9 MHz ${ }^{13} \mathrm{C}$ NMR spectrum of compound 6 in chloroform-d.
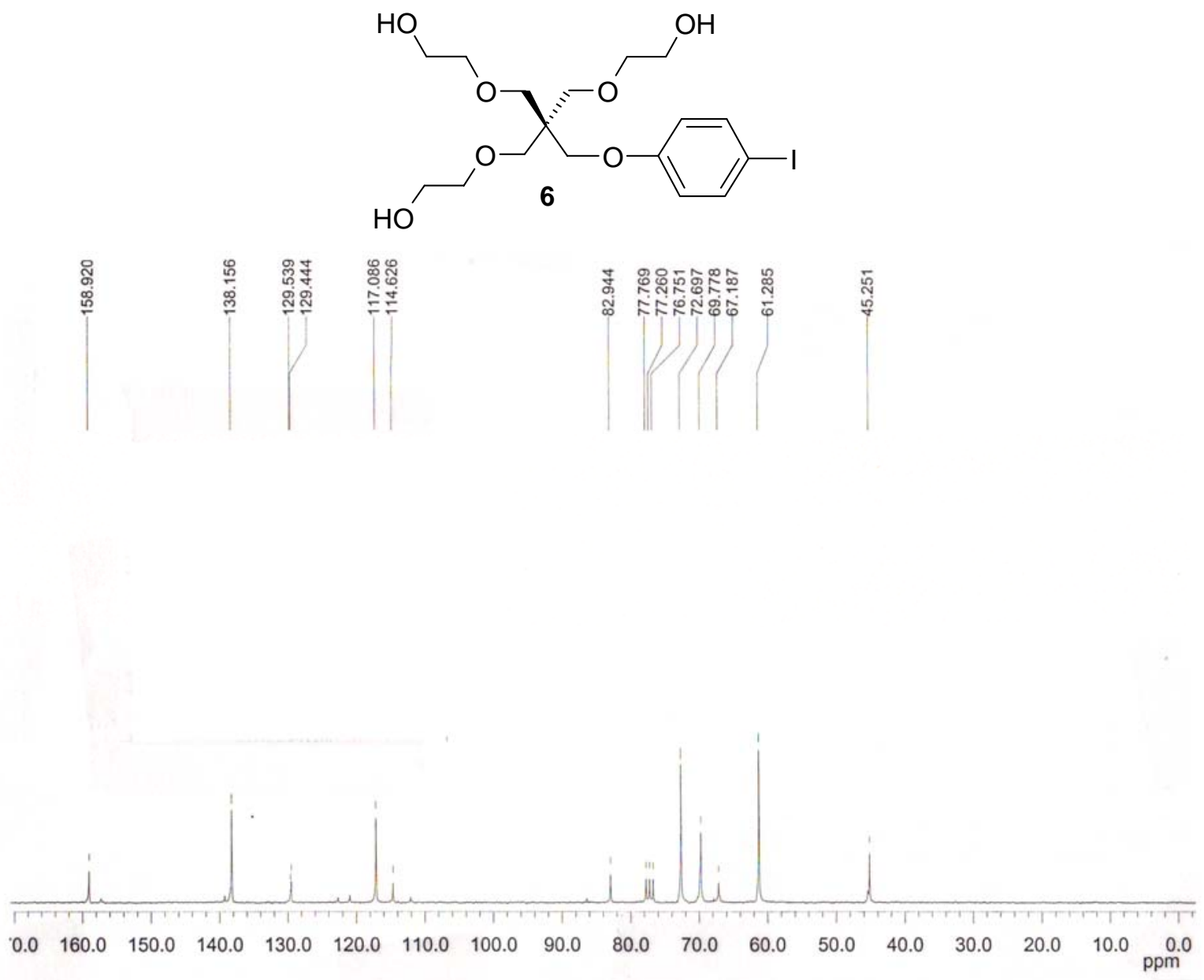
Part of the $500.13 \mathrm{MHz}{ }^{1} \mathrm{H}$ NMR spectrum of compound $\mathbf{1 0}$ in chloroform-d.
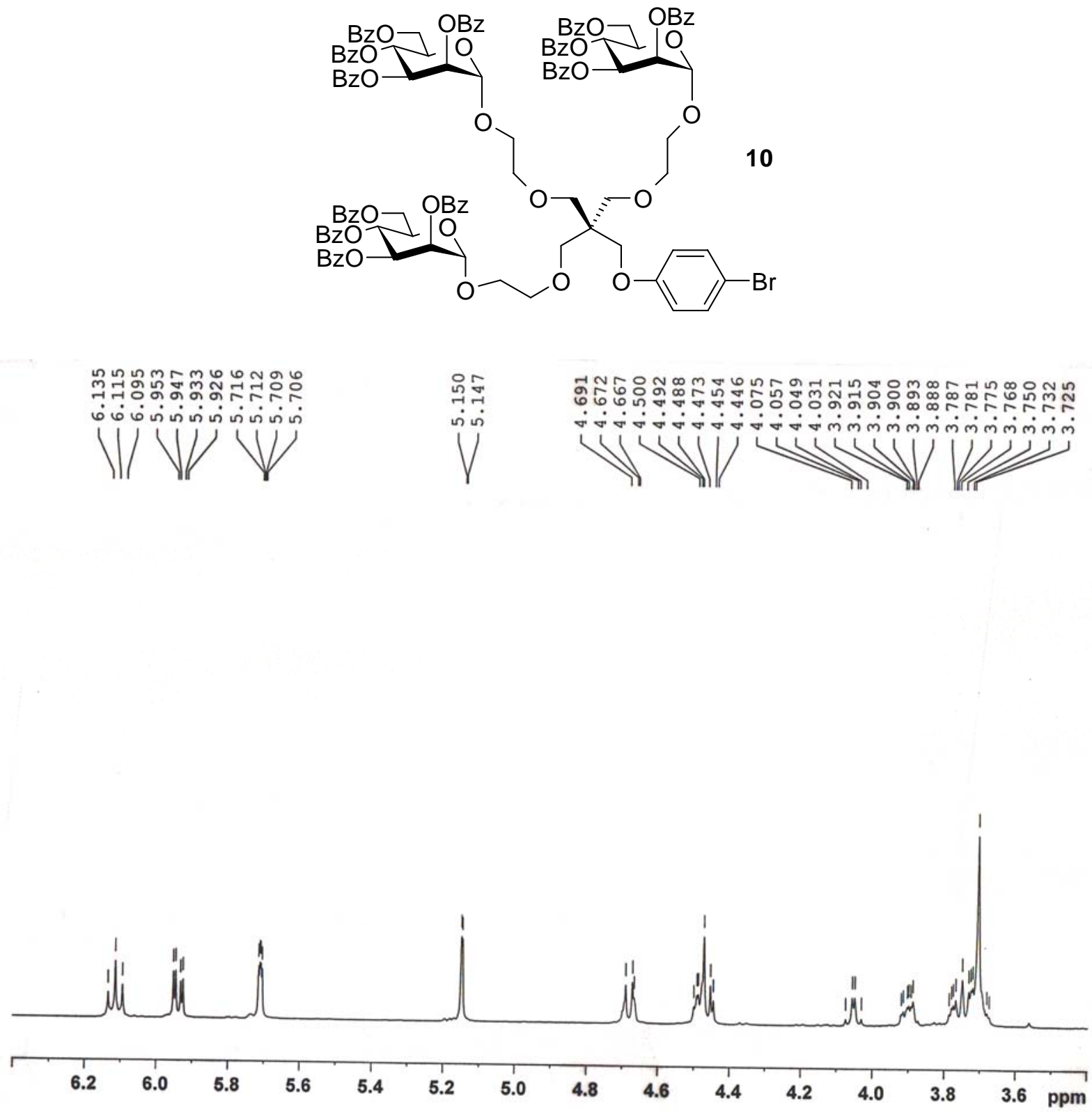
125.8 MHz ${ }^{13} \mathrm{C}$ NMR spectrum of compound $\mathbf{1 0}$ in chloroform-d.

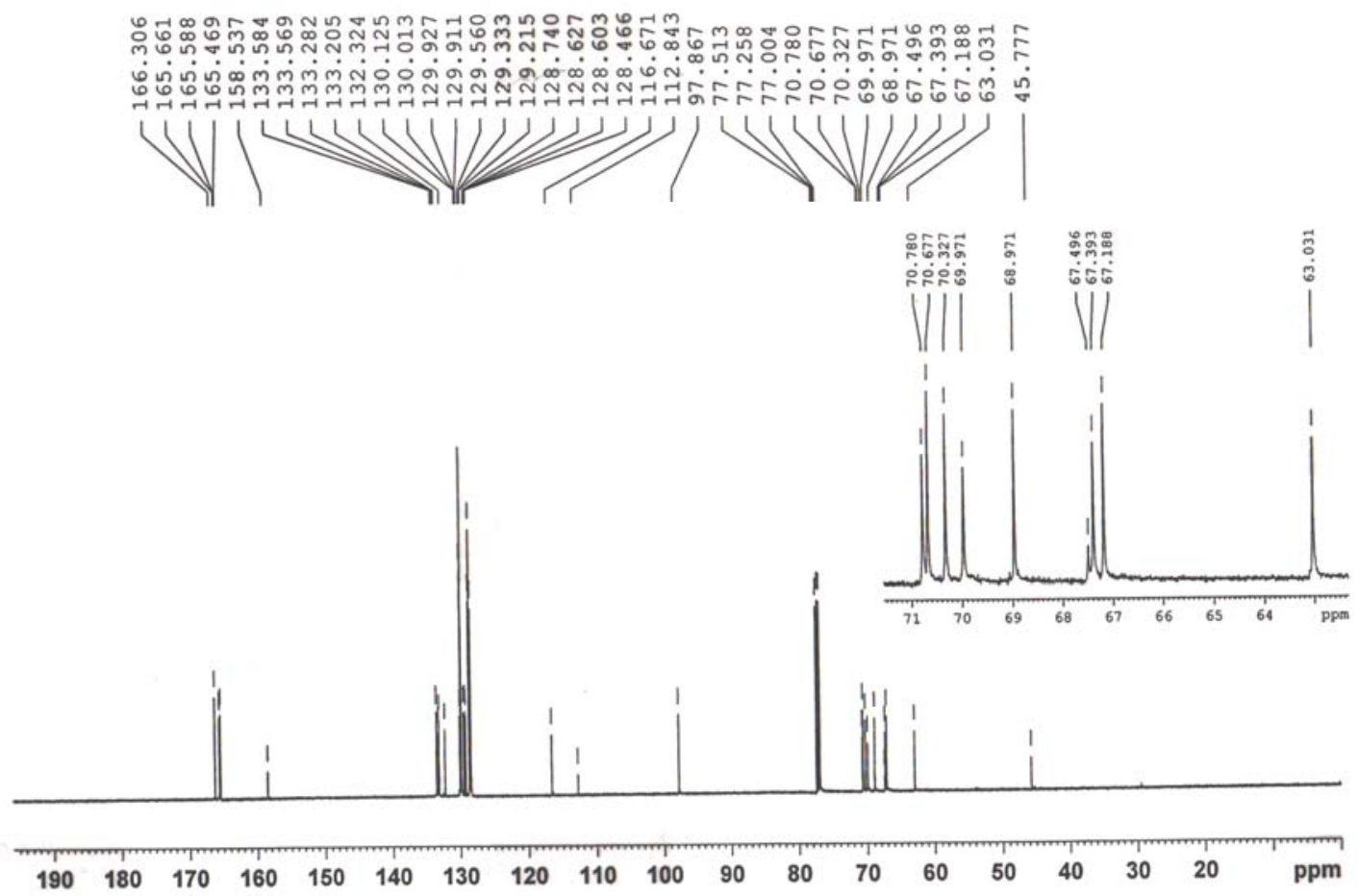


ESI mass spectrum of compound $\mathbf{1 0}$ on an ion-trap mass spectrometer. Top: the whole spectrum.

Bottom: Expansion of the molecular ion cluster. Note that $\mathrm{M}+\mathrm{Na}$ is calculated to have an $\mathrm{m} / \mathrm{z}$ value of 2179.6 , but because there are $119 \mathrm{C}$ and a $\mathrm{Br}$ in the structure, the $\mathrm{M}+1$ peak is larger, and the $\mathrm{M}+2$ peak is the base peak.
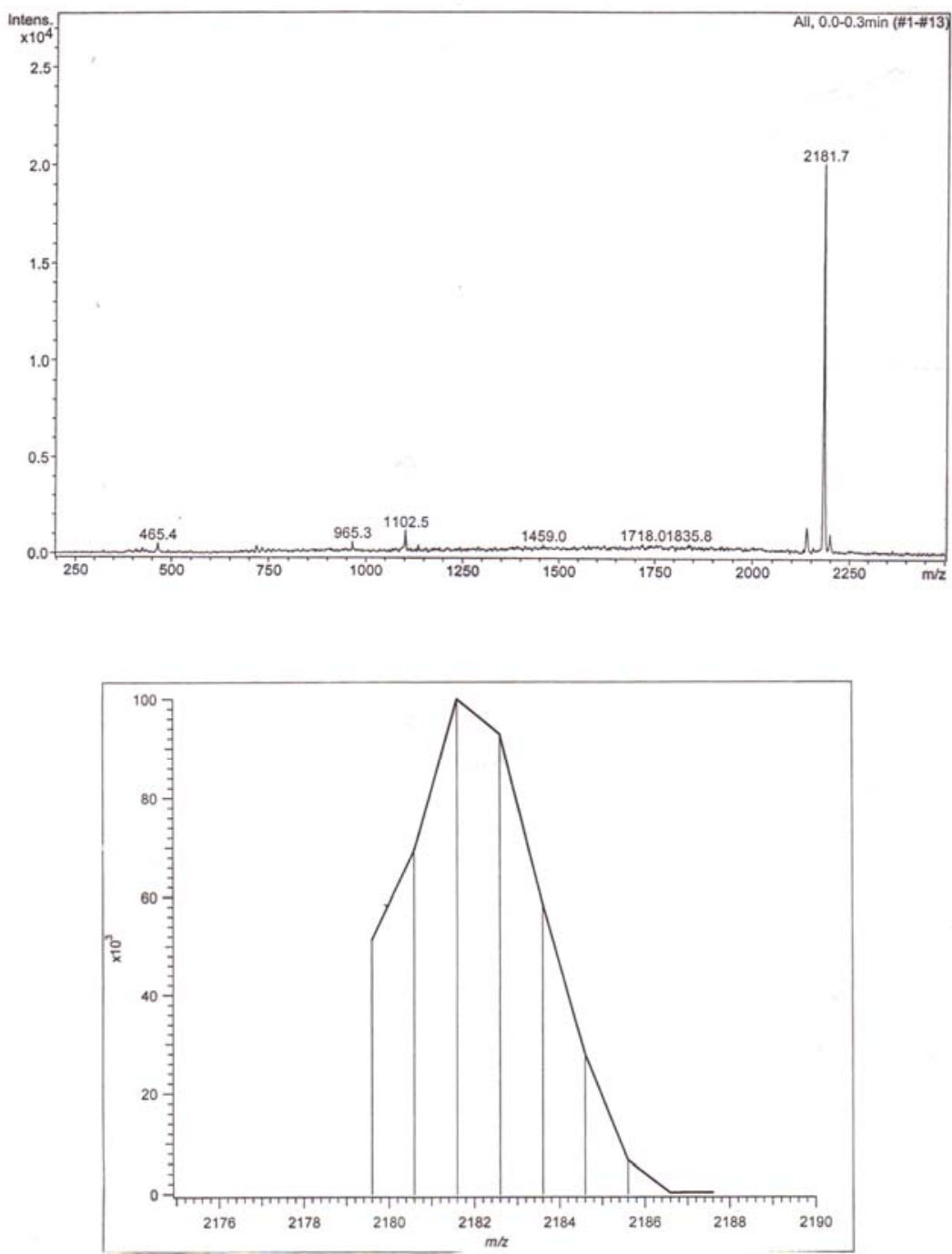
Part of the $500.13 \mathrm{MHz}{ }^{1} \mathrm{H}$ NMR spectrum of compound $\mathbf{1 1}$ in chloroform-d.
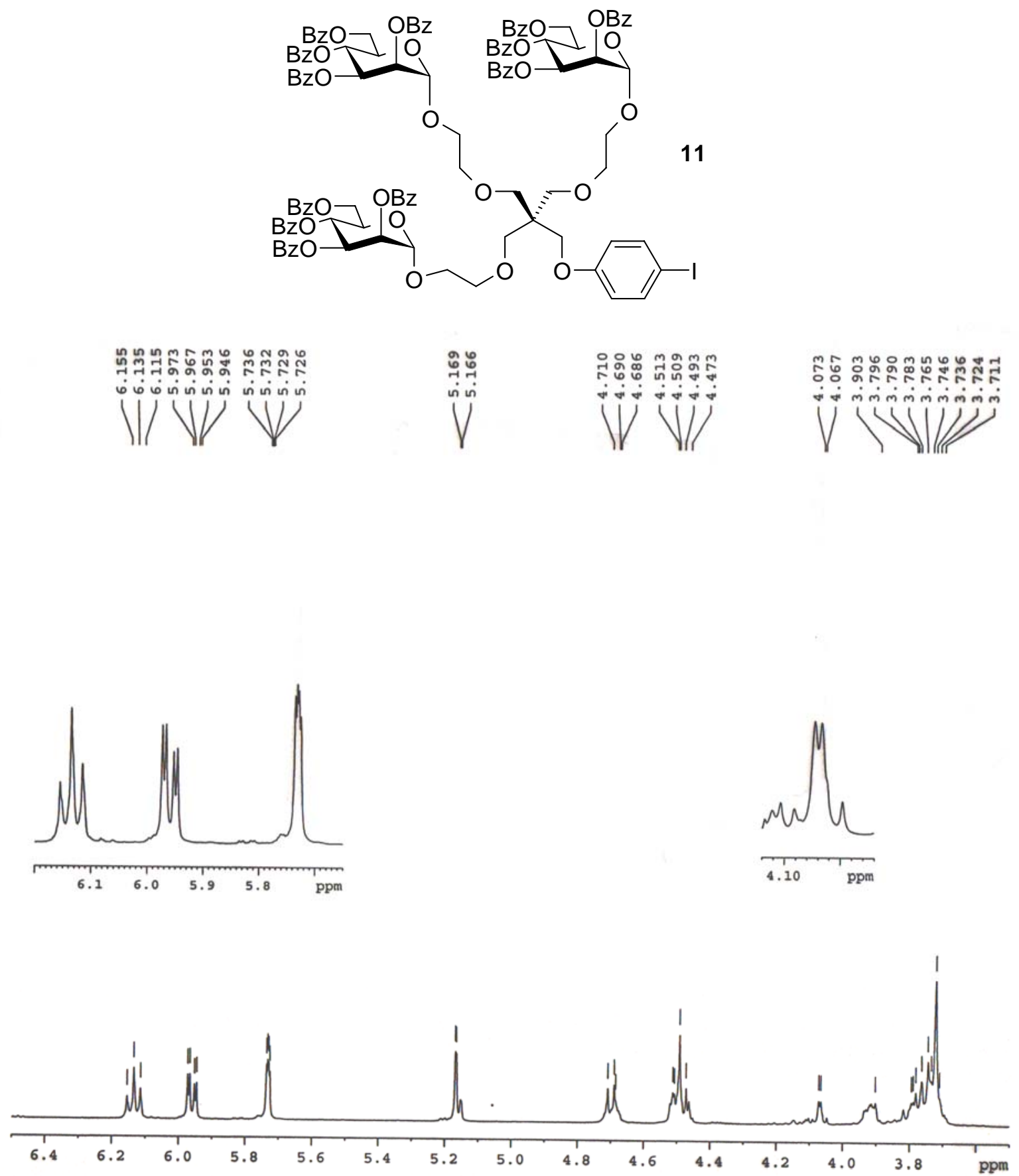
125.8 MHz ${ }^{13} \mathrm{C}$ NMR spectrum of compound $\mathbf{1 1}$ in chloroform-d.
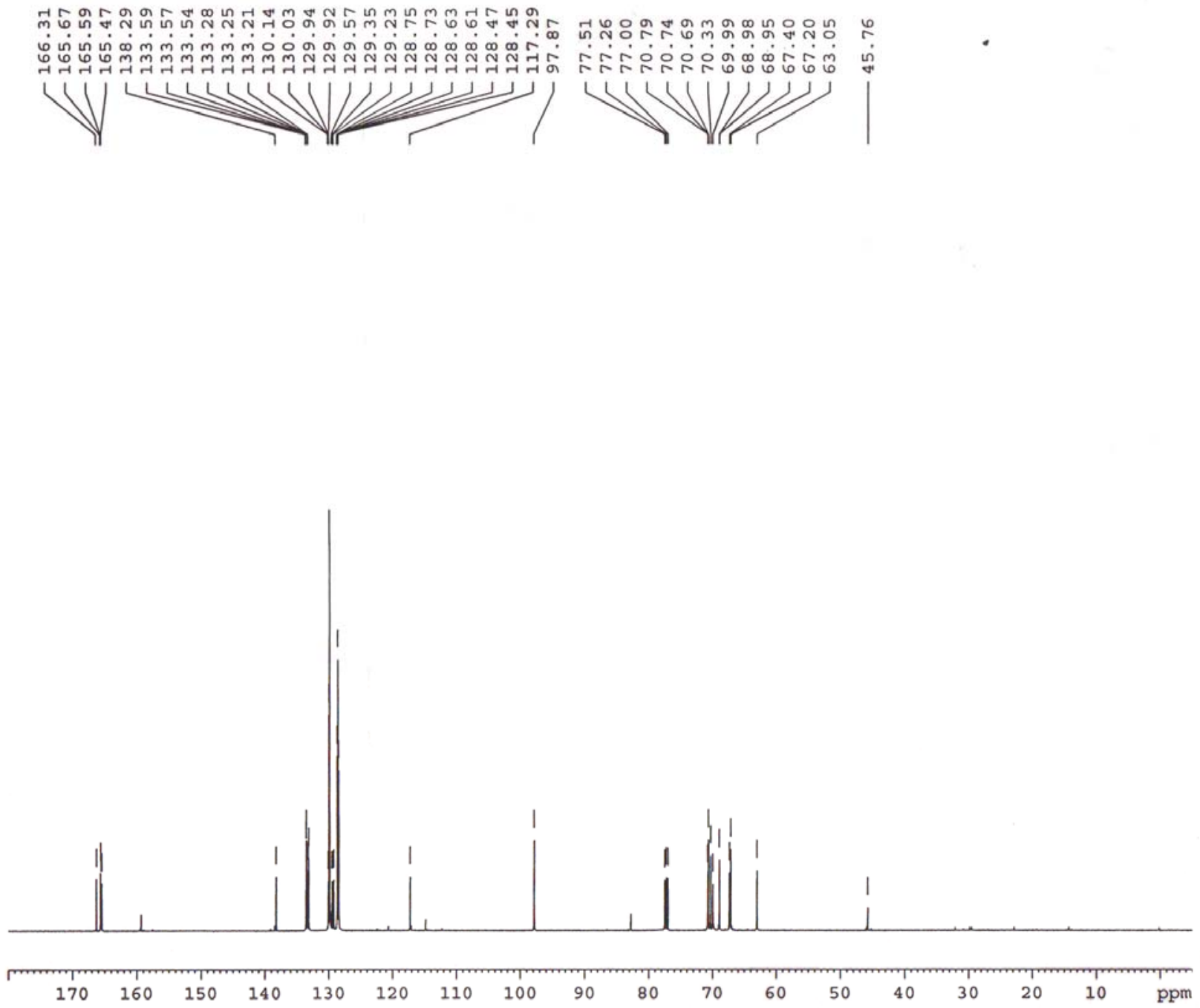
The molecular ion region of the MALDI mass spectrum of compound $\mathbf{1 1}$ recorded on a $9.4 \mathrm{~T}$ FT-

ICR mass spectrometer. The peak at $\mathrm{m} / \mathrm{z} 2227.546$ is the $\mathrm{M}+\mathrm{Na}$ peak.

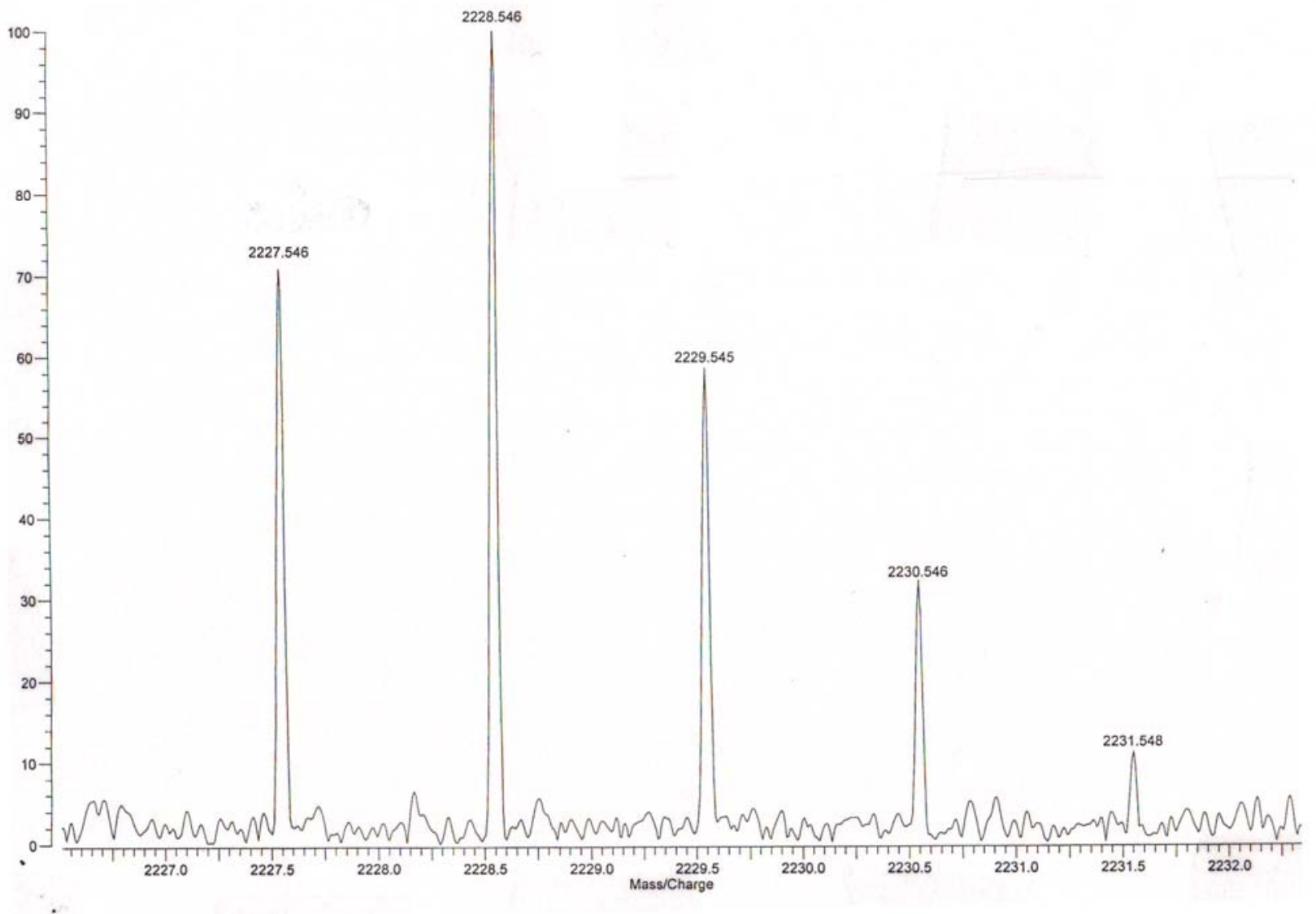


250.13 MHz ${ }^{1} \mathrm{H}$ NMR spectrum of compound 13 in dimethyl sulfoxide- $d_{6}$.<smiles>COc1ccc(C2OCC(CO)(CO)COC2O)cc1</smiles>
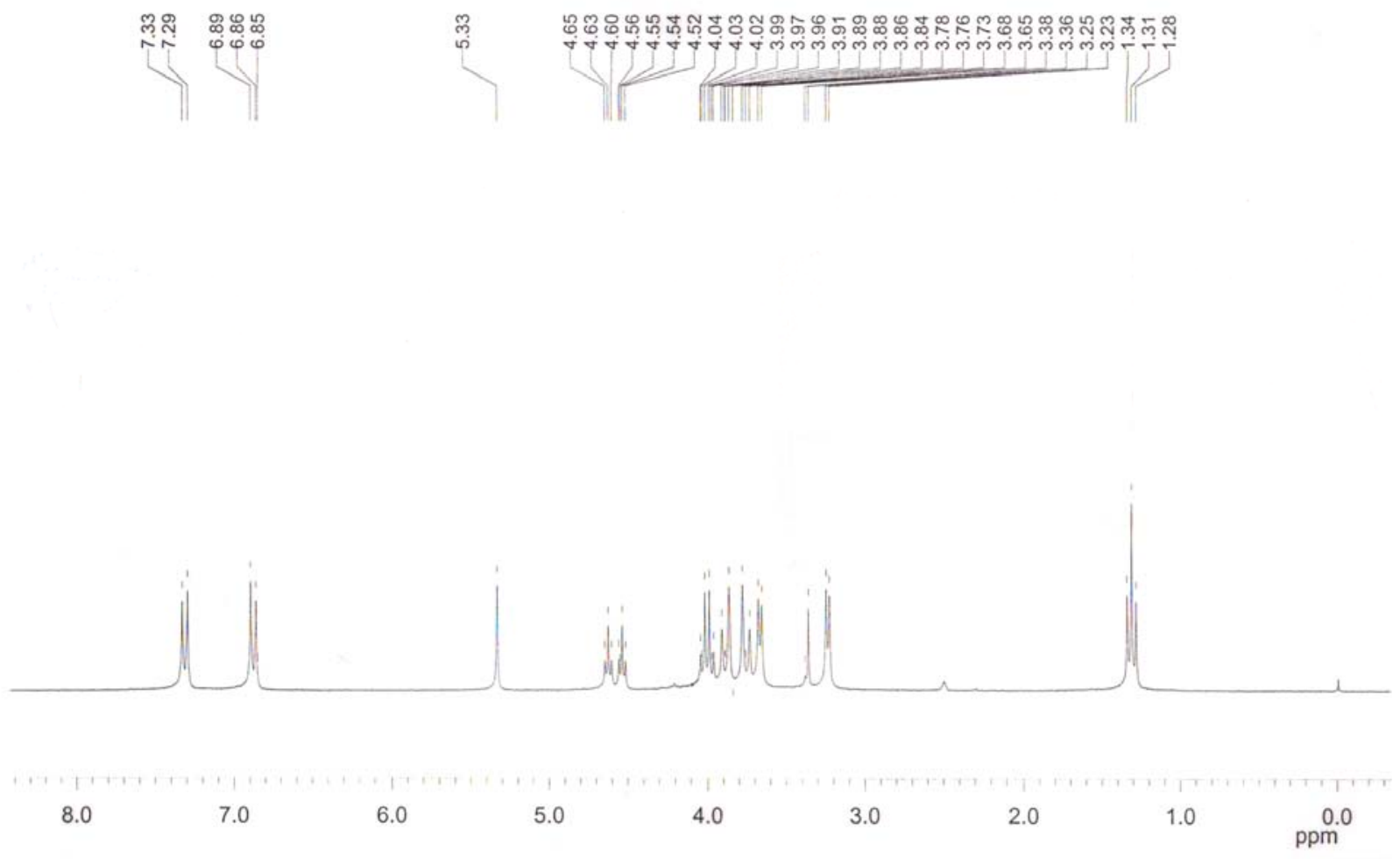
62.9 $\mathrm{MHz}{ }^{13} \mathrm{C}$ NMR spectrum of compound 13 in dimethyl sulfoxide- $d_{6}$.

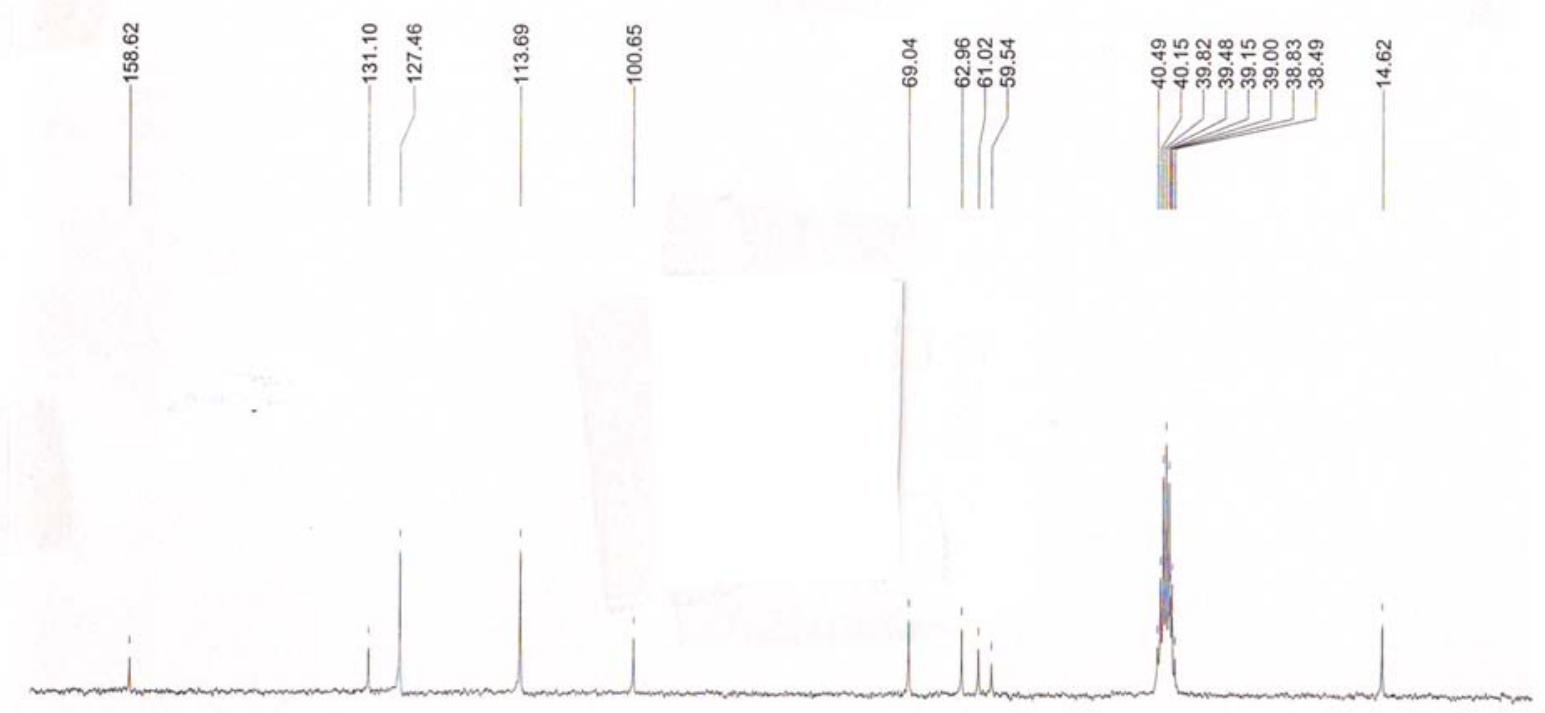

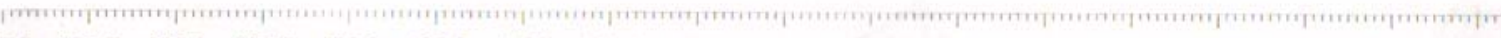
$\begin{array}{llllllllllllllllll}0.0 & 160.0 & 150.0 & 140.0 & 130.0 & 120.0 & 110.0 & 100.0 & 90.0 & 80.0 & 70.0 & 60.0 & 50.0 & 40.0 & 30.0 & 20.0 & 10.0 & 0.0 \\ \mathrm{ppm}\end{array}$ 
$250.13 \mathrm{MHz}{ }^{1} \mathrm{H}$ NMR spectrum of compound 15 in chloroform- $d$.

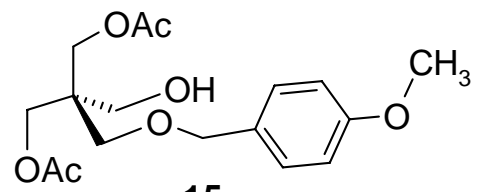

15
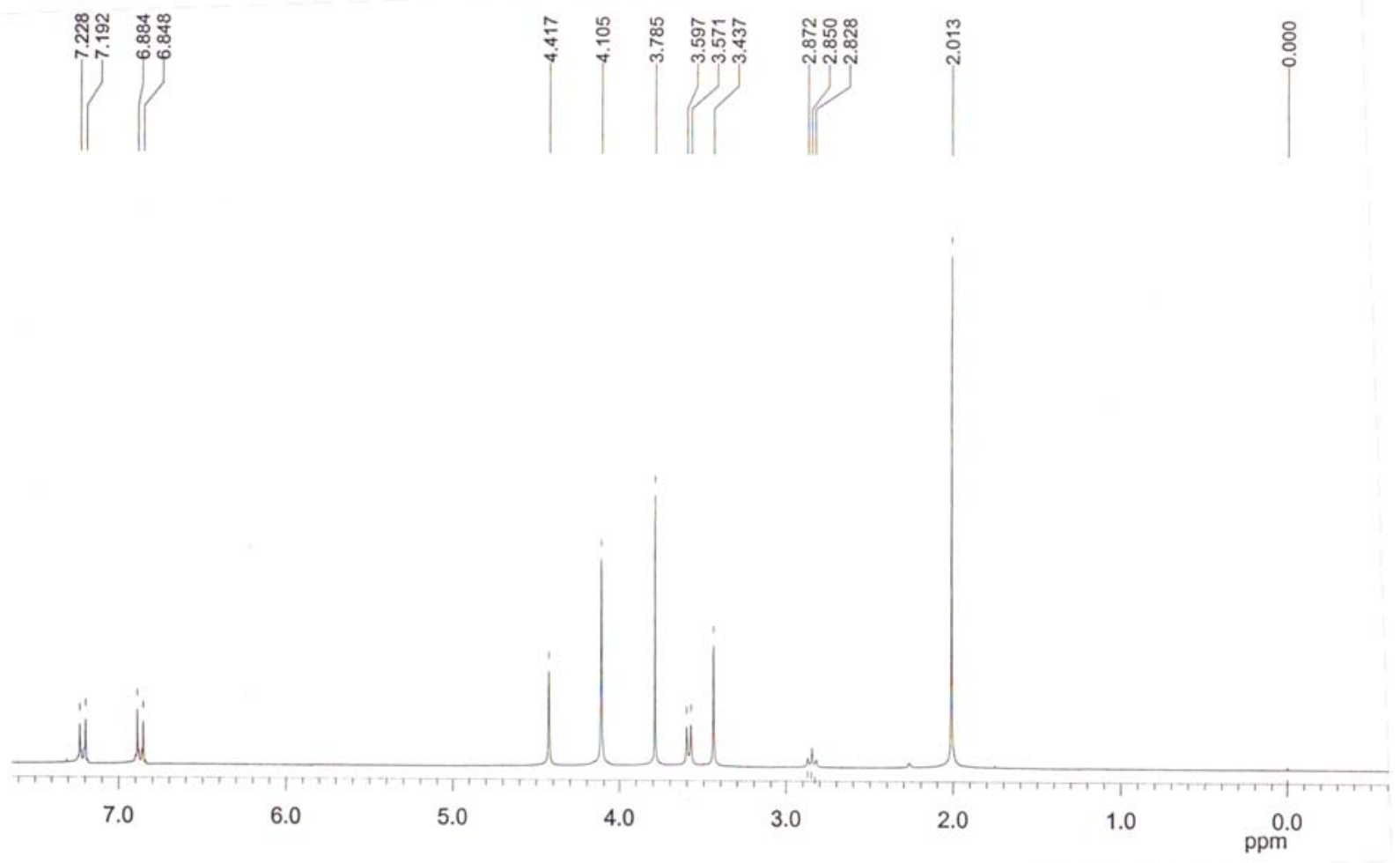
62.9 MHz ${ }^{13} \mathrm{C}$ NMR spectrum of compound 15 in chloroform- $d$.
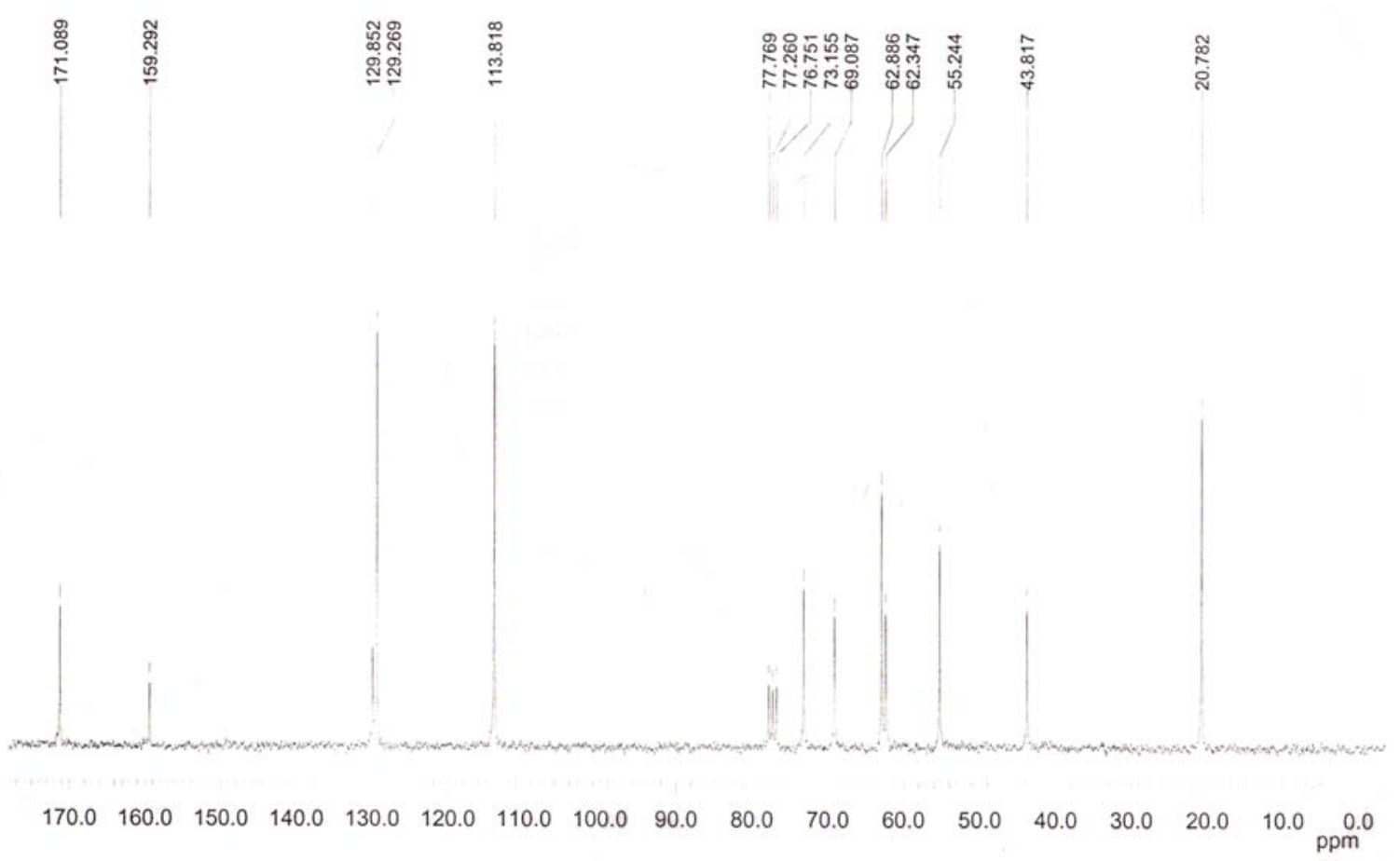
250.13 MHz ${ }^{1} \mathrm{H}$ NMR spectrum of compound 16 in chloroform-d.
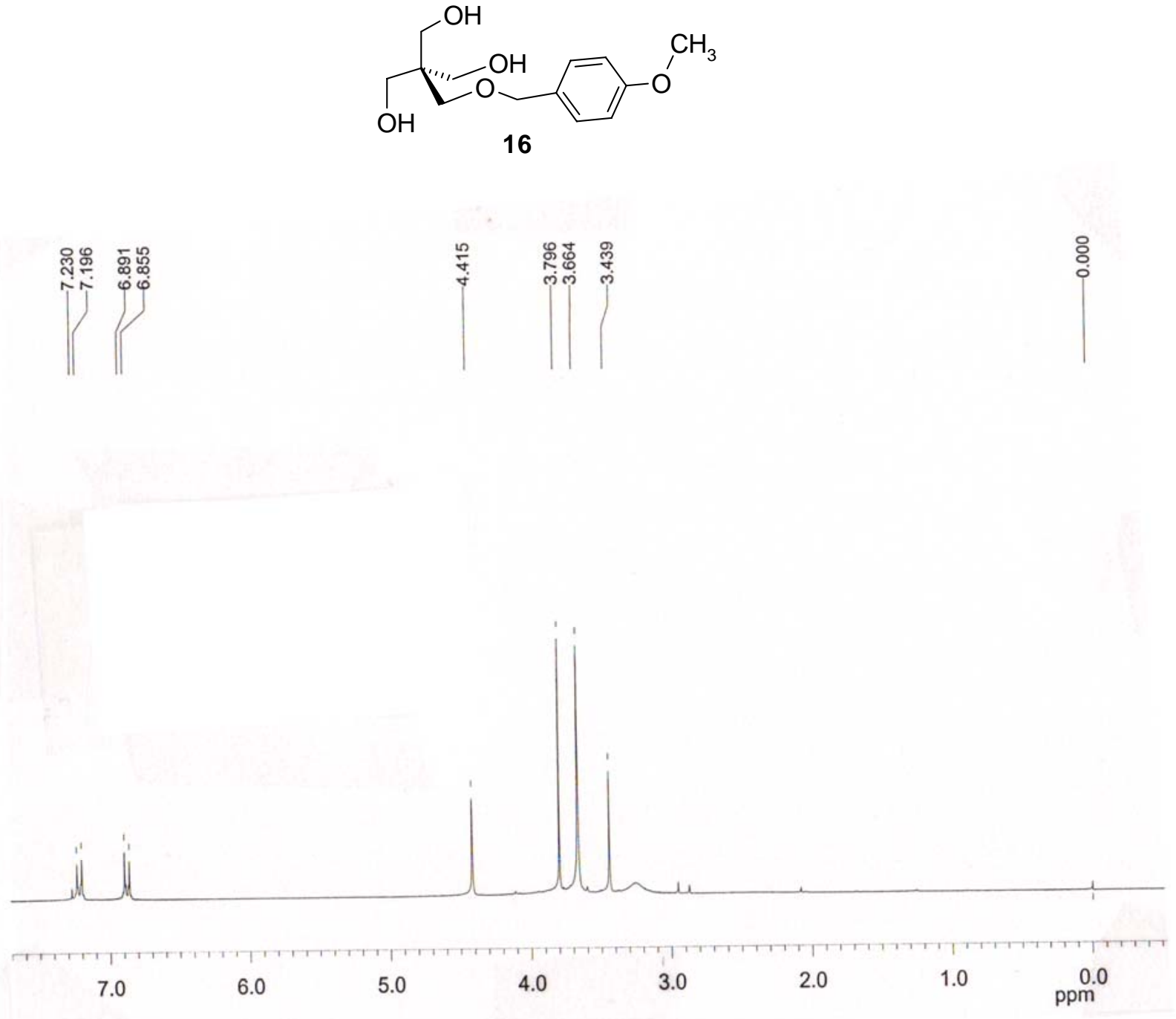
62.9 MHz ${ }^{13} \mathrm{C}$ NMR spectrum of compound $\mathbf{1 6}$ in chloroform- $d$.
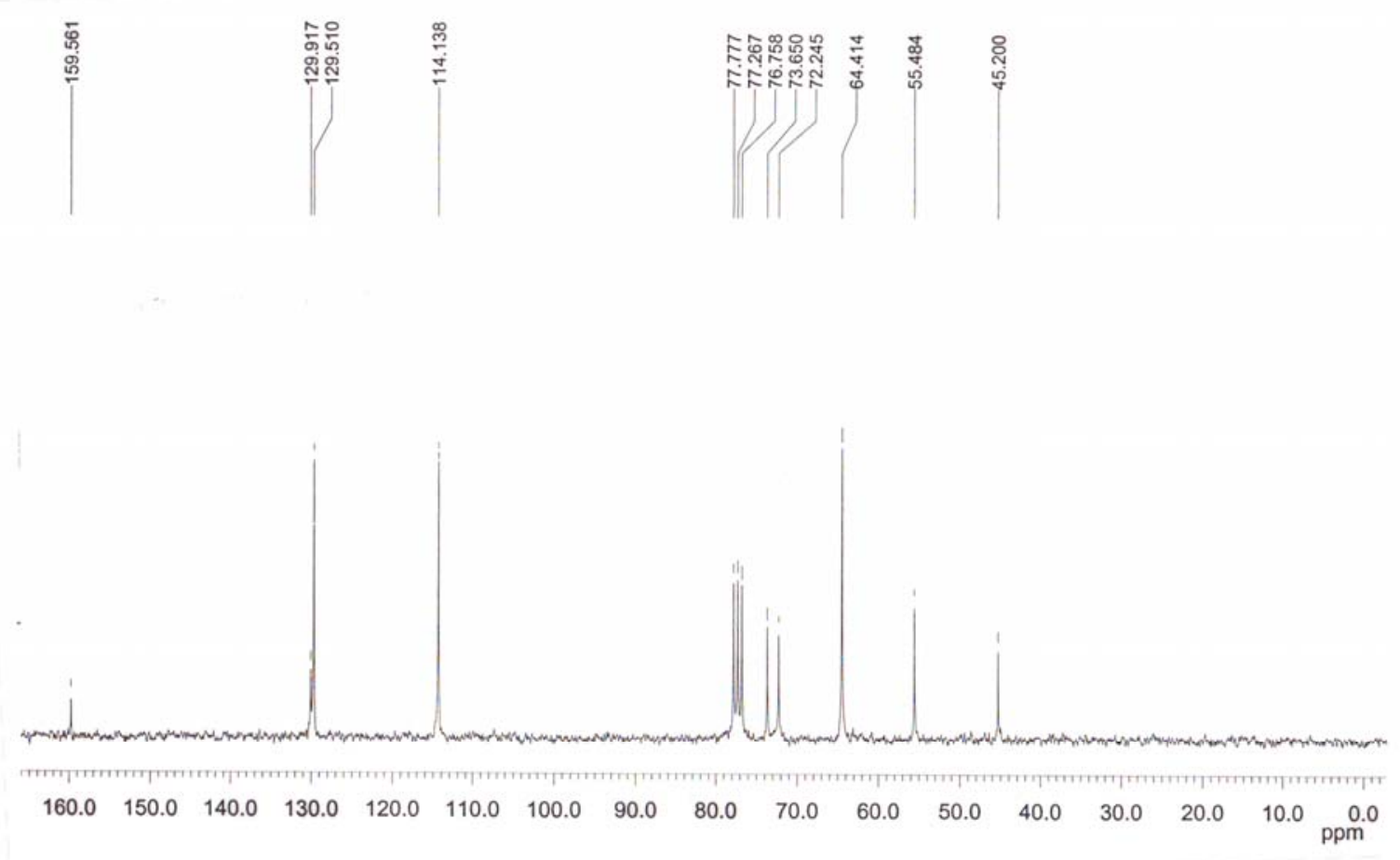
250.13 MHz ${ }^{1} \mathrm{H}$ NMR spectrum of compound 17 in chloroform-d.
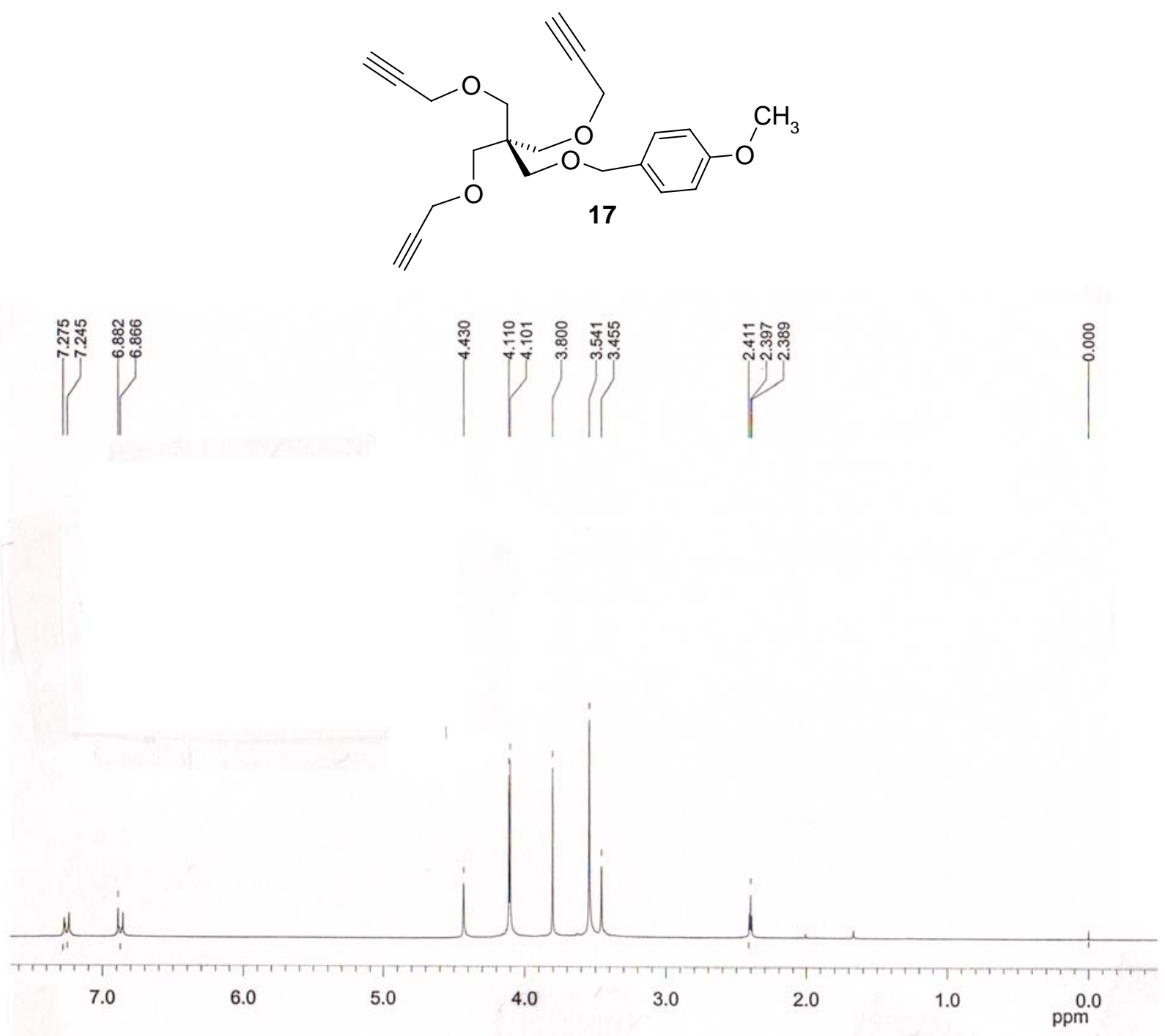